\title{
Questões de limite e povoamento: a produção de Orville Derby e Teodoro Sampaio na revista do Instituto Histórico e Geográfico de São Paulo (1895-1901)
}

Question of limit and settlement: the work of Orville Derby and Teodoro Sampaio on the journal of Historical and Geographical Institute of São Paulo (1895-1901)

Gerson Ribeiro Coppes Junior* gersoncoppes@hotmail.com

Resumo: A produção histórica do Instituto Histórico e Geográfico de São Paulo no início do século XX se inseriu em um contexto de mudanças políticas, econômicas, sociais e culturais. Na busca por uma hegemonia política na primeira república, os letrados sócios do Instituto participaram de uma construção histórica que buscou legitimar e justificar essa hegemonia. Ambicionava-se reconstruir a história nacional com fatos e vultos da história local. Neste artigo buscamos entender como e por que a escrita sobre os limites do estado de São Paulo e o povoamento do interior paulista por Orville Derby e Teodoro Sampaio, respectivamente, contribuíram para a escolha dos primeiros temas para a escrita da história em São Paulo no início do século XX. Foram selecionados 8 textos dos dois autores entre 1895 e 1901 para analisar os temas e enunciados presentes nesses estudos. Esses textos seriam de alguma forma complementares entre si, pois enquanto Derby delinearia este espaço, o estado de São Paulo, Sampaio "povoaria" esses limites produzindo um primeiro esboço de uma história que contemplava os temas que guiaram a produção histórica do Instituto posteriormente: a expansão e povoamento do interior do país.

Palavras-chave: Instituto Histórico, Teodoro Sampaio, Orville Derby

Abstract: The historical production of the Historical and Geographical Institute of São Paulo in the early twentieth century was inserted in a context of political, economic, social and cultural changes. In the search for a political hegemony in the First Republic, the "men of letters" members of the Institute participated in a historical construction that sought to legitimize and justify this hegemony. They aspired reconstruct the national history with facts and figures from the local history. In this article, we seek to understand how and why writing about the border and the settlement of São Paulo by Orville Derby and Teodoro Sampaio, respectively, contributed to the choice of the first subjects for the writing of history in São Paulo early in the twentieth century. There were selected eight works of the two authors between 1895 and 1901 to analyze the subjects and statements present in these studies. These texts would somehow complement each other, because while Derby outline this space, the state of São Paulo, Sampaio "populate" these limits producing a first draft of a history which included the themes that guided the historical production of the Institute on the years ahead: the expansion and settlement of the interior of the country.

Keywords: Historical Institute, Teodoro Sampaio, Orville Derby

*Mestrando em História pela Universidade Estadual Paulista (UNESP/Assis). 
Construindo uma história para a locomotiva do Brasil

“A história de São Paulo é a própria história do Brasil" (RIHGSP, 1895). Esta frase que aparecia no primeiro volume da Revista do Instituto Histórico e Geográfico de São Paulo (RIHGSP) não estava ali por acaso. Sendo a principal força econômica da Primeira República, principalmente por causa da cultura cafeeira, a intelectualidade paulista criou um discurso para justificar "a proeminência dessa elite (paulista), sobre todo o Brasil, identificando o Estado à Nação" (ABUD, 1985, p. 132-133). Esta frase evidenciava a diretriz para uma agenda política e historiográfica que se desenvolveria nas próximas décadas.

Kátia Abud ao estudar a historiografia produzida entre 1890 e 1930 afirma que neste processo de construção do passado, de uma nova história de São Paulo que atendesse aos interesses de sua elite política, o bandeirante surgiu como personagem principal. $\mathrm{O}$ bandeirante evocado pelos intelectuais paulistas, retomando seu papel na expansão territorial durante a época colonial, retomava também uma historiografia precedente desenvolvida no século XVIII que havia definido certas características ao bandeirante: "nobreza, valor, coragem, superioridade racial" (ABUD, 1985, p. 132). A retomada do bandeirante transpunha estes valores dos sertanejos do século XVII para a elite paulista do século XX, justificando seu projeto histórico e político no quadro da Primeira República, a criação de uma hegemonia paulista na federação forjando a imagem de locomotiva do país (LOVE, 1982, p. 297).

Neste período os letrados, motivados pelas ideias que circulavam na época, viam na educação um meio de atingir o progresso social e superar o atraso (FERREIRA, 2002, p. 96). A fundação do IHGSP se localizava nesse contexto onde a instrução foi reorganizada sendo acompanhada pela criação de instituições científicas, tais como: a Comissão Geográfica e Geológica de São Paulo (CGGSP), em 1886, o Museu Paulista (MP) e o Instituto Histórico e Geográfico de São Paulo (IHGSP), ambos em 1894. Estas instituições serviam como locais de divulgação científica, das ideias modernizadoras para o estado e para o país e também como locais de construção do discurso hegemônico sobre São Paulo. Os intelectuais que participaram destes institutos compartilhavam uma crença na ciência como uma possibilidade de promover o desenvolvimento de São Paulo, algo que ficava muito claro na atuação da CGGSP (FIGUEIRÔA, 1997). Ferreira afirma ainda, refletindo sobre o contexto de mudanças que o estado e sua capital passavam (SEVCENKO, 1992; PORTA, 2005), que essas instituições ajudaram a "fincar as tradições de uma região e um porto seguro na avalanche modernizadora" (FERREIRA, 2002, p. 97).

Inserido neste contexto, o IHGSP estava profundamente ligado à elite política e, consequentemente, ao poder executivo estadual. O Instituto foi um local de produção, divulgação e discussão desta nova história de São Paulo centrada na ocupação do interior do país. Sua composição social, sua relação com o estado, sua organização e objetivos seguiam o modelo traçado pelo Instituto Histórico e Geográfico Brasileiro, IHGB, que se constituiu no século XIX (CEZAR, 2011; GUIMARÃES, 1988; GUIMARÃES, 1995, 2007):

Havia, nesse novo estabelecimento, a intenção de imprimir uma marca ao mesmo tempo comum ao modelo ilustrado e civilizado idealizado pelo IHGB, e por outro lado bastante diversa da forma original, já que se buscava destacar primordialmente uma suposta especificidade paulista. (FERREIRA, 2002, p. 109)

\footnotetext{
${ }^{1}$ Nas citações das fontes os títulos foram mantidos no original e a escrita foi modificada para a gramática e ortografia atual.
} 
A criação do IHGB em 1838 norteou a produção histórica oitocentista para a construção da nação brasileira recém independente criando símbolos, imagens, um discurso nacional, tendo como base as noções de civilização e progresso do iluminismo (GUIMARÃES, 1988). O Instituto Histórico e Geográfico de São Paulo inaugurado 60 anos depois se colocava contra o projeto histórico centralizado no IHGB ambicionando reescrever a história do Brasil escrita até então elegendo heróis e símbolos paulistas (FERREIRA, 2002, p. 110). Desta forma, os sócios da agremiação se colocaram na tarefa de reescrever a história de São Paulo centrada na expansão e povoamento do interior do país durante a época colonial construído uma história onde a parte sobrepunha o todo.

Tendo em vista que uma ampla bibliografia tratou da construção dessa identidade regional, que outros aspectos ainda são possíveis de serem estudados? Na busca de entender essa reescrita da história de São Paulo focamos a pesquisa no espaço institucional do IHGSP e nos trabalhos publicados na RIHGSP. A análise dos trabalhos de Orville Derby e Teodoro Sampaio, que tratam da questão de limites e sobre o povoamento de São Paulo, buscou a resposta para algumas questões: Quais imagens sobre São Paulo são construídas por esses trabalhos? Como e por que esse espaço está sendo definido? Questionar sobre estes aspectos, naturalizados com o tempo até chegar aos dias atuais, ajuda a entender não somente como e por que a história foi escrita em determinado período e determinada época, mas também entender a sua influência nesse projeto político. ${ }^{2}$

\section{Definir os limites com história}

A questão da divisa de São Paulo com Minas Gerais era um problema que persistia desde o século XVIII. A supressão da capitania de São Paulo entre 1749 e 1765 e a descoberta de ouro na região sul do atual estado de Minas Gerais ocasionou a disputa entre paulistas e mineiros (DERBY, 1898-1899, p. 454). Percorrendo sem solução os séculos XVIII e XIX, um novo episódio dessa disputa em 1894 levou o então presidente do estado de São Paulo, Bernardino de Campos, requerer à Repartição de Estatística e do Arquivo do Estado a reunião dos documentos referentes à questão de limites na tentativa de solucionar a disputa. Os documentos descobertos foram publicados no volume XI dos Documentos interessantes para a história e costumes de São Paulo (ARQUIVO..., 1986). A organização desta série foi uma das primeiras iniciativas de Antônio de Toledo Piza e Almeida à frente da direção do Arquivo, publicação iniciada em 1894 (MENDES, 2010, p. 113). Na organização desse volume, Piza teria a colaboração de Orville Derby. Em 1898 Toledo Piza, também com a colaboração de Derby, publicou o livro Questões de Divisas entre São Paulo e Minas Gerais como resultado da análise dos documentos publicados no volume IX dos Documentos Interessantes. Este livro havia sido publicado anteriormente, no mesmo ano, como suplemento do jornal Correio Paulistano. No artigo do periódico Piza dimensiona a importância da questão:

Estas questões não podem ficar eternamente sem uma solução definitiva, porque são fontes de contínuos choques entre os governos dos dois Estados e frequentemente perturbam a paz e a harmonia que devem existir entre os seus habitantes. Uma solução definitiva, imediata,

\footnotetext{
${ }^{2}$ Próximo dos problemas colocados pelo campo de estudo da história da historiografia, ao mesmo tempo que se carrega a possibilidade do questionamento epistemológico, também possibilita o historiador questionar o seu próprio tempo. Abdicando da busca por uma verdade histórica, busca-se a desnaturalização destas, agora entendidas no plural, verdades. Perceber o passado como uma construção expõe escolha, omissões, possibilidades. Cf. MALERBA, Jurandir (org.). A História Escrita. Teoria e história da historiografia. São Paulo: Contexto, 2006.
} 
que corte de uma vez para sempre, pela raiz, todos os germens de futuras discórdias, se impõe como uma das mais ardentes aspirações dos bons cidadãos e como uma das maiores necessidades para a paz e harmonia dos povos (PIZA, 1898, p. 7).

No primeiro volume da RIHGSP Orville Derby publicou o trabalho A denominação "Serra da Mantiqueira” (1895) sobre a questão da divisa entre São Paulo e Minas Gerais. Tendo em vista que a Serra da Mantiqueira era utilizada como divisa entre os dois estados desde o século XVIII, se buscava determinar qual seria o traçado correto da serra. Derby aponta que a imprecisão das informações topográficas do tempo em que surge a questão até o momento em que escrevia motivou a escolha de tal região, montanhosa, para a divisa pois poderia ser manipulada pelas autoridades de acordo com suas pretensões.

Derby também apontava em seus estudos o oportunismo das autoridades mineiras sobre os territórios disputados. Ao elencar autoridades que desempenharam papel importante nestes eventos Derby expõe a figura de Francisco Martins Lustosa, guarda-mor de Santa Anna do Sapucahy, afirmando como ele teria evitado o avanço de Minas Gerais sobre os territórios paulistas durante o século XVIII:

\footnotetext{
É possivel que sem esse movimento não se tivesse dado esta supressão, mas neste caso os mineiros, obtendo pacificamente a desejada posse deste distrito, não teriam encontrado barreira alguma para a sua expansão no sertão que é hoje a parte mais rica do Estado de São Paulo, e, na redistribuição das capitanias que era inevitável São Paulo teria sido, talvez, ainda mais sacrificado do que foi em favor das capitanias auriferas de Minas Gerais, Goiás e Mato Grosso ficando como Rio de Janeiro limitado a uma estreita faixa junto ao litoral (DERBY, 1899-1900, p. 228).
}

Expõe-se uma imagem de oposição entre São Paulo e a Coroa, oposição que é construída a partir de episódios como a supressão da capitania de São Paulo e as ações da Coroa na questão de limites, cuja intervenção teve "efeitos decisivos sobre o desenvolvimento histórico da capitania de São Paulo”. Esse sentido fica claro quando se afirma como São Paulo poderia ver seu território reduzido a uma faixa de terra no litoral em detrimento das minas de ouro. Se Lustosa pode ter sido determinante para a supressão da capitania, isso se justificava pois conteve as pretensões de Minas Gerais:

O efeito benéfico da ação de Lustosa foi o de firmar em São Paulo a ideia de seu antigo direito pelo Sapucai que, embora não vencedora, tem sido sempre uma barreira a expansão indefinida de Minas Gerais, que por pouco não se apoderou de todo o vale do Mogi-Guaçu e Rio Grande (DERBY, 1899-1900, p. 228)

Ele reitera a defesa do território também na trajetória de Jeronymo Dias Ribeiro, comandante do registro de Itapeva, afirmando:

Se nesta época ele e os seus companheiros de luta tivessem sido menos ativos e vigilantes ou os governadores menos prontos e firmes nas providências reclamadas, os mineiros se teriam infalivelmente estabelecido na antiga estrada de Goiás, e S. Paulo teria perdido os importantes distritos de Casa Branca, S. José do Rio Pardo, Mococa, Caconde, Cajuru, São Simão, Ribeirão Preto, Batatais e Franca. (DERBY, 1899-1900, p. 235)

Apesar da discussão da questão de limites empreendida por Derby, de fato, ao fim dessa série de estudos não havia sido alcançada uma solução pata tal problema. Seria necessário esperar mais 50 anos para que tal objetivo fosse alcançado. ${ }^{3}$

\footnotetext{
${ }^{3}$ O jornal OESP de 08 de fevereiro de 1958 publicou matéria que expunha a solução definitiva do litigio entre São Paulo e Minas Gerais: Firmado convenio sobre a questão de limites S. Paulo-Minas Gerais. FIRMADO CONVÊNIO SOBRE A QUESTÃO DE LIMITES S. PAULO-MINAS GERAIS. OESP, São Paulo, 08 fev. 1958, p. 8.
} 
Orville Derby ainda se voltaria para a questão de limite com o estado do Paraná no trabalho Notas sobre a questão de limites entre estados de São Paulo e Paraná (DERBY, 1900-1901). Após a emancipação do estado do Paraná, em 1853, o limite entre os dois estados, sendo em sua maioria determinado pelo Rio Paranapanema, seguiu sem grandes contestações. Exceção era a área que não contava com esse divisor natural, na bacia hidrográfica do rio Ribeira do Iguapé. Derby, assim como na questão de limites com Minas Gerais, utiliza dos documentos oficiais para construir uma história sobre a divisa entre os estados. No caso paranaense, as autoridades desse estado são descritas como incapazes, ineficientes ou ainda desinteressados na questão referida:

\begin{abstract}
Por um infeliz acaso nenhum dos mapas mais ou menos oficiais do Estado do Paraná representa este ribeirão.
\end{abstract}

[...] as autoridades paranaenses não definem claramente a linha divisória que pretendem e não explicam como o trecho citado (pelo ribeirão da Pedra Preta e em completo acordo com as pretensões do Apiai) justifica a posse do território situado fora da bacia desse ribeirão [...]

[...] o Governo do Paraná não tem tratado de justificar sua posse de ambas as margens desse ribeirão (DERBY, 1900-1901, p. 24-25)

O ribeirão que Derby faz referência é o Ribeirão da Pedra Preta que integrava a principal área de contestação entre os dois estados. Derby aponta que em 1876 havia sido publicado pela Inspetoria de Terras e Colonização o mapa da província do Paraná empreendido pelo engenheiro Carlos Rivierre. Porém, segundo Derby, ao mesmo tempo que as autoridades paranaenses defendiam limites que correspondiam ao traçado de Rivierre, eles também defendiam uma linha abaixo dessa, sem estar ligada a nenhuma outra linha de limite, e que estava de acordo com o traçado defendido pela câmara da cidade paulista de Apiaí. Esse aspecto reforçava a imagem que Derby constrói das autoridades paranaenses, apontando incoerências em suas ações. $\mathrm{O}$ autor afirma, por fim, que as autoridades do Paraná concediam mais a São Paulo do que se reclamava. Porém, Derby pontua que tendo acesso somente aos documentos presentes no Arquivo do Estado de São Paulo o estudo "é necessariamente incompleto e talvez incorreto em diversos pontos" (DERBY, 1900-1901, p. 26).

Os problemas de divisas na RIHGSP estavam concentrados nestas duas áreas, Minas Gerais e Paraná. Entendemos assim, que a definição de limites de São Paulo não somente delimitava, mas também consolidava e justificava este espaço físico, além de expor as relações de poder de uma elite local que almejava a hegemonia política no quadro nacional:

Os documentos dessa contenda são aqui apresentados, não somente como uma contribuição para a história da questão de limites em si, mas também para a história das localidades e para do desenvolvimento geográfico de uma parte do território nacional tão importante que a sua elevação à categoria de Estado independente tem sido muitas vezes lembrada. [grifo nosso] (DERBY; ARQUIVO DO ESTADO DE SÃO PAULO, 1896, p. XXXII)

Buscando apreender a formação histórica da divisa, retomasse o processo que as cria e delimitasse um espaço físico para o estado de São Paulo que, na impossibilidade de se voltar as antigas divisas, se defende as existentes. Temístocles Cezar (2005) ao analisar o papel desempenhado pela geografia na historiografia oitocentista, essencialmente no caso IHGB, ponta como ela auxiliou na expansão das fronteiras e também na construção do imaginário territorial da nação em construção. Para Cezar, enquanto a história representava a nação no tempo, a geografia seria a nação no espaço. Se considerarmos o papel do saber geográfico e a construção de uma delimitação e legitimação de limites 
apresentadas nos trabalhos de Derby, é um paralelo possível de ser feito, apesar das particularidades que deveriam ser pensadas para aplicar tal lógica ao caso paulista. No entanto, se utilizarmos tal afirmação, a história construindo um processo e a geografia constituindo o espaço, onde estaria a história que complementaria os estudos de Derby? Analisaremos a seguir os trabalhos publicados por Teodoro Sampaio que focaram no povoamento de São Paulo em busca de compreender como a história da dinâmica do povoamento contribuiu para construir uma nova história de São Paulo dentro desses limites.

\section{Preencher com história os limites}

Não bastava definir os limites do estado era necessário preencher esses limites com uma nova história de São Paulo. Teodoro Sampaio foi um dos primeiros sócios do IHGSP a se voltar para as diretrizes de pesquisa definidas por Capistrano de Abreu (1853-1927), em um período de mudanças da matriz histórica brasileira, (BENZAQUEN, 1988; GONTIJO, 2013; OLIVEIRA, 2013; PERREIRA, 2002; PEREIRA, 2010) se voltando para o empreendimento historiográfico que ocupou grande parte dos letrados nos anos finais do século XIX e durante as primeiras décadas do século XX: a expansão e o povoamento do interior do Brasil.

No primeiro volume da RIHGSP, em 1895, Sampaio publicou o artigo A posse do Brazil Meridional - fundação da primeira colônia regular dos portugueses em S. Vicente (1895), três anos depois, no volume quatro publicou São Paulo de Piratininga no fim do Século XVI (1898-1899), no volume cinco O sertão antes da conquista (Século XVII) (1899-1900) e no volume seis oferecia ao público seu quarto estudo, S. Paulo no Século XIX (1900-1901). Sampaio construiu uma história do povoamento do estado apresentando um sentido litoral-interior/sertão. Publicados entre 1895 e
1901, os textos apresentavam a conquista do sertão pelos paulistas como resultado tanto da adaptação do mestiço ao meio, quanto da predestinação geográfica: o sul do Brasil, em comparação ao norte, tinha um ambiente mais propício a sua inserção no continente além do clima mais ameno:

O destino de cada uma das duas metades da colonia, diante do problema da conquista, estava, pois, perfeitamente assinalado na constituição geográfica dos respectivos territórios. O paulista, pelo seu habitat, tinha que ser o bandeirante por excelência. A conquista dos sertões estava no seu destino histórico. (SAMPAIO, 1899-1900, p. 87)

Sampaio retomava as teorias raciais da época e as invertia. Se o clima tropical degenerava a raça, o sul da colônia tinha um clima ameno. Se o mestiço era um tipo racial inviável e um obstáculo ao alcance da civilização ela ainda poderia ser alcançada se vencesse o meio. As teorias raciais e deterministas começaram a ser incorporadas no Brasil durante a virada do século XIX e encontraram recepção entre os grupos de intelectuais que buscavam novos projetos para modernizar o Brasil. A "degeneração mulata" defendida por Louis Agasciz poderia explicar o atraso do país pelo grande número de mestiços, mas também teria efeito reverso condenando parte daquela elite. O caminho encontrado para escapar de um prognóstico negativo, reservado para o futuro do Brasil por estas teorias, foi adaptá-las a realidade nacional. Capistrano de Abreu trazendo este debate para a historiografia uniu o determinismo racial ao determinismo geográfico de Buckle. Vencer o meio também era um caminho para atingir a civilização. (SKIDMORE, 1989; VENTURA, 1991; SCHWARCZ, 1993; FERRETI, 2004).

Traçando um panorama do povoamento do estado até o século XIX, Teodoro Sampaio afirma que:

O povoamento do território prosseguia, contudo, numa marcha regular do centro 
para a periferia, e na proporção que as lavouras iam reclamando terra novas.

As grandes estradas tradicionais, partindo de São Paulo, pontuava-se por núcleos de população, que cresciam lentamente e que passavam de simples povoados a freguesias e vilas com intervalos de tempo mais ou menos longos (SAMPAIO, 1900-1901, p. 181)

Sampaio esboça uma representação histórica de um Marco Zero, colocando São Paulo como centro de uma "viação interior" se dividindo em vários troncos. As estradas tradicionais as quais Sampaio faz referência são os caminhos utilizados pelos bandeirantes: no leste, pelo vale do Paraíba, a estrada do Rio de Janeiro pelo qual os taubateanos penetraram nas minas; Ao norte, a estrada do sul de Minas, em direção a Ouro Fino e Caldas; No noroeste, buscando as minas além dos cerrados e campos de São Carlos e Franca, a estrada de Goiás; No centro-oeste, o Tietê, a estrada das monções partindo de Itu; No sul, a rota dos tropeiros, outrora caminho para as bandeiras do Guaíra; E por último, o tronco em direção ao mar, a estrada de Cubatão (SAMPAIO, 1900 -1901, p. 163-164).

Sampaio comparava essas vias a artérias e dedos de uma mão gigantesca que se abria sobre o território paulista. O povoamento seguindo o rumo das estradas deixava um espaço vazio entre estes troncos. Entre os dedos se abria o sertão, o deserto. A associação entre deserto e sertão retomava a acepção original da palavra construída pelos portugueses, um local vasto, longínquo, pouco habitado, mas também estava presente outro sentido construído durante a colonização do Brasil. Se o litoral centralizava a vida política e econômica da colônia representando a civilização, o sertão além de ser o espaço interior da colônia também é o espaço do bárbaro, um espaço a ser conquistado pela civilização (AMADO, 1995). Desta forma, a fundação de cidades ao longo destes caminhos assinalava "as várias e suces- sivas estações da conquista civilizadora que avança” (SAMPAIO, 1900-1901, p. 181).

Se a história de São Paulo se desenhava pela conquista do sertão, na última metade do século XIX quatro aspectos eram responsáveis pelo progresso de São Paulo: a cultura do café, a primeira estrada de ferro, a colonização e imigração e a autonomia da República. Sampaio neste ponto apontava vários aspectos importantes. Se o café era o grande responsável pela posição econômica de São Paulo na virada do século XIX, a ferrovia auxiliou o escoamento da produção e sua expansão. Além disso, estas duas imagens retomam o sentido da fronteira avançando principalmente pela necessidade de terras.

A questão do imigrante, além disso, retomava a discussão em torno da modernização do país e a viabilidade do tipo nacional no fim do século XIX. O homem livre e pobre mantido a margem da sociedade do trabalho até a abolição da escravidão era tido como incapaz, ocioso e insubordinado. A solução para substituir o escravo foi a escolha do imigrante, correspondendo a uma ideia de progresso e civilização associado ao branco europeu (NAXARA, 1998, p. 46).

Os quatro aspectos apontados por Sampaio para o progresso de São Paulo no século XIX também apontava diretamente para sua atuação na CGGSP, pois retomavam os problemas ligados a cultura cafeeira que motivaram sua criação em 1886: disponibilidades de solos, transporte e escoamento da produção e a necessidade de mão de obra. A atuação de Sampaio na CGGSP criava uma ligação com Orville Derby, pela participação de ambos nesta instituição, e também os inseria no processo de modernização do estado de São Paulo almejado pela elite paulista que se relacionava com a cultura do café e, por consequência, com a ocupação e povoamento do território paulista durante o século XIX e 
XX. Se a questão de limites produz um outro, aqui temos um processo semelhante desta produção de alteridade. O sertão associado a imagem de espaço do bárbaro se torna aquilo que esta sociedade não quer ser e para isso ele deveria ser transformado pela modernidade. A exploração do oeste paulista, e Sampaio havia participado das primeiras expedições da CGGSP ao oeste paulista em 1886 (SAMPAIO, 2002), se transforma na conquista deste espaço bárbaro, o sertão, que deveria ser civilizado, racionalizado e aproveitado economicamente.

\section{Considerações Finais}

Ao analisar a produção histórica de Orville Derby e Teodoro Sampaio encontramos alguns temas que estariam presente durante a formação e consolidação do
IHGSP. O processo de construção deste espaço, perceptível nos trabalhos de Derby e Sampaio, se inseria nas diretrizes expostas por Capistrano de Abreu que marcaram a historiografia desse período, entre o fim do século XIX e início do século XX: a expansão e povoamento do interior do país. Desta forma, os trabalhos desses letrados seriam de certa forma complementares entre si. Enquanto Derby delineava os limites desse território paulista, Sampaio expunha o processo de povoamento. Enquanto a história construía São Paulo no tempo, a geografia construía São Paulo no espaço.

Sampaio também retomava as discussões em torno das teorias raciais e a discussão sobre a modernização do país presente nos intelectuais desse período. Afim de evitar o prognóstico negativo que estas teorias relegavam ao país os intelectuais adaptaram essas teori-

\section{Referências bibliográficas}

\section{Revista do Instituto Histórico e Geográfico de São Paulo}

Ao leitor. RIHGSP, São Paulo, v 1, 1895.

Dedicado a questão de limites entre Minas Gerais e São Paulo. RIHGSP, São Paulo, v.24, 1926.

DERBY, Orville. A denominação “Serra da Mantiqueira”. RIHGSP, São Paulo, v.1, 1895.

. São Paulo e Minas Geraes, antigas divisas. RIHGSP, São Paulo, v.4, 1898-1899.
. Primeira phase da questão de limites entre São Paulo e Minas Geraes no século XVIII. RIHGSP, São Pau- $\overline{\text { lo, v.5 }}, 1899-1900$.

. Notas sobre a questão de limites entre estados de São Paulo e Paraná. RIHGSP, São Paulo, v.6, 1900-1901.

SAMPAIO, Theodoro. A posse do Brazil Meridional - fundação da primeira colônia regular dos portugueses em S. Vicente. RIHGSP, São Paulo, v.1, 1895.

. São Paulo de Piratininga no fim do Século XVI. RIHGSP, São Paulo, v.4, 1898-99.

. O sertão antes da conquista. RIHGSP, São Paulo, v.5, 1899-1900.

. S. Paulo no século XIX. RIHGSP, São Paulo, v.6, 1900-1901.

Fontes Auxiliares

ARQUIVO DO ESTADO DE SÃO PAULO. Documentos Interessantes para a História e Costumes de S. Paulo. Vol. XI. Divisas de S. Paulo e Minas Gerais. São Paulo: Espindola, Siqueira e Comp., 1896.

PIZA, Antônio de Toledo. Divisas de São Paulo e Minas Gerais. Correio Paulistano, São Paulo, 18 set. 1898 . Suplemento, p. 7. 


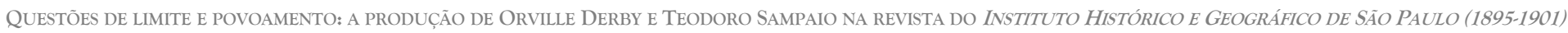

FIRMADO CONVÊNIO SOBRE A QUESTÃO DE LIMITES S. PAULO-MINAS GERAIS. O Estado de São Paulo, São Paulo, 08 fev. 1958

Livros e Artigos de Periódicos

ABREU, João Capistrano de. Necrológio de Francisco Adolfo de Varnhagen, Visconde de Porto Seguro. In. Ensaios e Estudos: crítica e história, $1^{\mathrm{a}}$ série. Rio de Janeiro: Civilização Brasileira; Brasília: INL, 1975.

ABUD, Katia. O sangue intimorato e as nobilíssimas tradições. São Paulo, Tese (Doutorado), Universidade de São Paulo, 1985.

AMADO, Janaína. Região, Sertão, Nação. Estudos Históricos, Rio de Janeiro, n. 15, 1995.

CEZAR, Temístocles. Lições sobre a escrita da história: as primeiras escolhas do IHGB. A historiografia brasileira entre os antigos e os modernos. In: GUIMARÃES, Lucia Maria Paschoal. (Org.) et al. Estudos de Historiografia brasileira. Rio de Janeiro: FGV, 2011.

FERREIRA, Antônio Celso. A Epopeia Bandeirante: letrados, instituições, invenção histórica, 1870-1940. São Paulo: UNESP, 2002.

FERRETI, Danilo. A Construção da paulistanidade: Identidade, historiografia e política em São Paulo (18561930). São Paulo, Tese (Doutorado), Universidade de São Paulo, 2004.

FIGUEIRÔA, Silvia F. de Mendonça. As ciências geológicas no Brasil: uma história social e institucional, 1875 1934. São Paulo: Hucitec, 1997.

GONTIJO, Rebeca. O velho vaqueano: Capistrano de Abreu (1853-1927): memória, historiografia e escrita de si. Rio de Janeiro: 7 Letras, 2013.

GUIMARÃES, Lucia Maria Paschoal. Debaixo da imediata proteção imperial: o Instituto Histórico e Geográfico Brasileiro (1838-1889). Revista do Instituto Histórico e Geográfico Brasileiro, jul.-set. 1995.

. Da escola palatina ao silogeu: Instituto Histórico e Geográfico Brasileiro (1889-1938). Rio de Janeiro: Museu da República, 2007.

GUIMARÃES, Manoel Luís Salgado. Nação e Civilização nos Trópicos: o Instituto Histórico Geográfico Brasileiro e o projeto de uma história nacional. Estudos Históricos, Rio de Janeiro, n. 1, 1988.

LOVE, Joseph. A Locomotiva: São Paulo na federação brasileira 1889-1937. Rio de Janeiro: Paz e Terra, 1982.

MALERBA, Jurandir (org.). A História Escrita. Teoria e história da historiografia. São Paulo: Contexto, 2006.

MENDES, André Oliva Teixeira. Os Documentos interessantes para a história e costumes de São Paulo: subsídios para a construção de representações. São Paulo, Dissertação (Mestrado), Universidade de São Paulo, 2010.

NAXARA, Márcia Capelari. Estrangeiro em sua própria terra: representações do brasileiro (1870-1920). São Paulo, Annablume, 1998.

OLIVEIRA, Maria da Glória de. Crítica, Método e Escrita da História em João Capistrano de Abreu. Rio de Janeiro: Editora FGV, 2013.

PEREIRA, Daniel M. Descobrimentos de Capistrano. A História do Brasil "a grandes traços e largas malhas". Rio de Janeiro, Tese (Doutorado), Pontifícia Universidade Católica do Rio de Janeiro, 2002.

PEREIRA, Mateus Henrique de Faria; SANTOS, Pedro Afonso Cristovão dos. Odisseias do conceito moderno de história: "Necrológio de Francisco Adolfo de Varnhagen", de Capistrano de Abreu, e "O pensamento histórico no 
Brasil nos últimos cinquenta anos”, de Sérgio Buarque de Holanda, revisitados. Revista IEB, nº 50, set. /mar. 2010, p. 27-78.

PORTA, Paula (org.). História da cidade de São Paulo - A cidade na primeira metade do século XX, 1890-1954. São Paulo: Paz e Terra, 2004. V. 3.

SAMPAIO, Teodoro. O rio São Francisco e a Chapada Diamantina. São Paulo: Companhia das Letras, 2002.

SCHWARCZ, Lilia Moritz. O Espetáculo das Raças: cientistas, instituições e questão racial no Brasil 1870-1930. São Paulo: Companhia das Letras, 1993.

SEVCENKO, Nicolau. Orfeu extático na metrópole: São Paulo, sociedade e cultura nos frementes anos 20. São Paulo: Companhia das Letras, 1992.

SKIDMORE, Thomas. Preto no branco: Raça e Nacionalidade no Pensamento brasileiro. Rio de Janeiro: Paz e Terra, 1989.

VENTURA, Roberto. Estilo tropical: História cultural e polêmicas literárias no Brasil. São Paulo: Cia. das Letras, 1991.

Submissão: $26 / 12 / 2015$

Aceite: $23 / 06 / 2016$ 